\title{
Tubal prolapse after total laparoscopic hysterectomy
}

Received: 6 January 2005 / Accepted: 29 July 2005 / Published online: 22 November 2005

(C) Springer-Verlag Berlin / Heidelberg 2005

\begin{abstract}
Prolapse of a uterine tube is a rare event after hysterectomy with adnexal conservation. It has been described in the literature after abdominal or vaginal hysterectomy. We report two cases occurring after total laparoscopic hysterectomy. Both patients presented with pelvic pain and vaginal discharge. The diagnosis was clinically suspected and was investigated using transvaginal ultrasonography. The diagnosis may be helped by histopathology. The diagnosis was confirmed by laparoscopy, and both patients were managed laparoscopically without complications.
\end{abstract}

\section{Introduction}

Prolapse of a Fallopian tube at the level of the vaginal vault is a rare complication of hysterectomy with ovarian conservation. Thus, it is rarely suspected and poorly diagnosed. We describe two cases of pyosalpinges resulting from hernia of the uterine tube through the vaginal vault in women who had undergone a laparoscopic hysterectomy. The diagnosis was suspected clinically, and confirmed by laparoscopic visualization. Both cases were treated laparoscopically.

W. C. Ang $(\varangle) \cdot$ Y. Lenglet · R. Botchorishvili $\cdot$ H. Roman M. Canis · G. Mage

Department of Obstetrics and Gynaecology and Reproductive Medicine, Polyclinique de L'Hôtel-Dieu CHU, 13 Boulevard Charles de Gaulle, Clermont-Ferrand, France

E-mail: cang@chu-clermontferrand.fr

Fax: + 33-4-73931706

Y. Lenglet $\cdot$ R. Botchorishvili $\cdot$ G. Mage

Department of Obstetrics and Gynaecology,

Hospitalier Général - Matérnité de Riom, Riom, France

\section{Case presentation}

Case 1

The first patient was 50 years old when she underwent a total laparoscopic hysterectomy with ovarian conservation in 1993 for menorrhagia and suspected adenomyosis. This was an uncomplicated procedure. She became menopausal shortly after and received transcutaneous hormonal replacement therapy.

She presented 10 years later with pelvic pain, fever, and leucorrhoea. Clinical examination found a mass in the posterior fornix that was painful to the touch. It was not possible to accurately identify the lesion under speculum examination, apart from the malodorous discharge. Ultrasound examination showed a collection that was suspicious of a hydrosalpinx: a cystic mass, predominantly anechoic, of an oblong sausage shape, without vegetations, and showing hypervascular walls on Doppler imaging.

Laparoscopy confirmed the presence of a large rightsided pyosalpinx, fixed and adherent to the vaginal vault. Puncture of this lesion brought forth a purulent fluid (Fig. 1). Treatment consisted of a bilateral salpingo-oophorectomy with resection of the likely sinus and opening of the vaginal vault (Fig. 2). The vault was then sutured with interrupted figure-of-eight sutures using poliglecaprone 0 at two points (Fig. 3). This procedure was performed completely laparoscopically.

\section{Case 2}

This patient was a 43-year-old G6P5, operated on in 2002, who underwent a total laparoscopic hysterectomy with ovarian conservation for metrorrhagia. She was noted to have a large fibroid uterus. The operation and the postoperative course were uneventful.

Of note, the patient had type II diabetes and had an increased body mass index. She presented 6 months later with vaginal bleeding, malodorous vaginal discharge, 


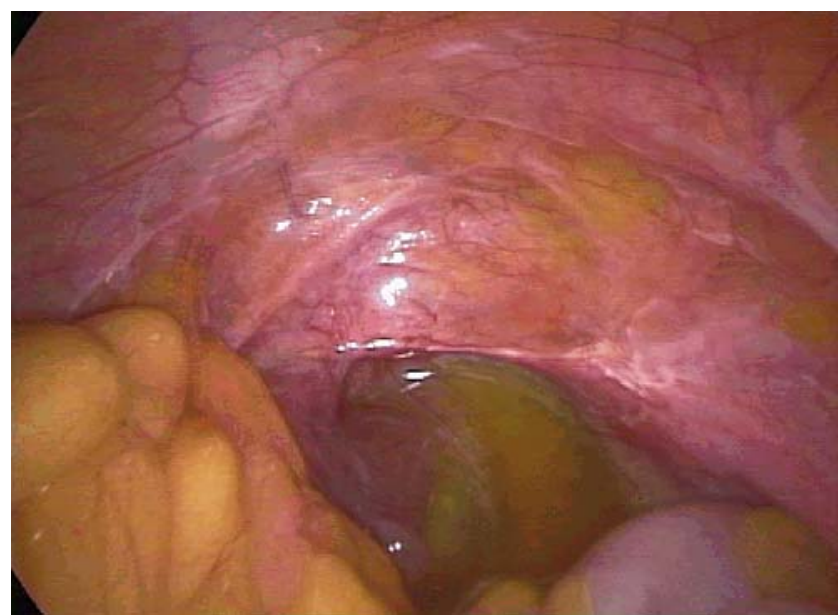

Fig. 1

and dyspareunia. Clinically, the fimbrial end of the uterine tube could be seen at the left angle of the vaginal vault (Fig. 4). A biopsy was taken, and the finding was reported as a mucoid polyp with inflammation and suspicion of neoplastic cells. Ultrasound examination showed a possible hydrosalpinx.

Laparoscopy was undertaken and confirmed partial separation of the vaginal vault with incarceration of the left uterine tube (Fig. 5). A left salpingo-oophorectomy was carried out, with resuturing of the vaginal vault with figure-of-eight sutures at two points with poliglecaprone 0 . Once again, this was performed completely laparoscopically. The histology confirmed an infected hydrosalpinx.

\section{Discussion}

Prolapse of the fallopian tube is a rare but recognized complication after hysterectomy. A Medline search was performed using keywords "uterine tube", "oviduct" and "fallopian tube" in conjunction with "prolapse". A

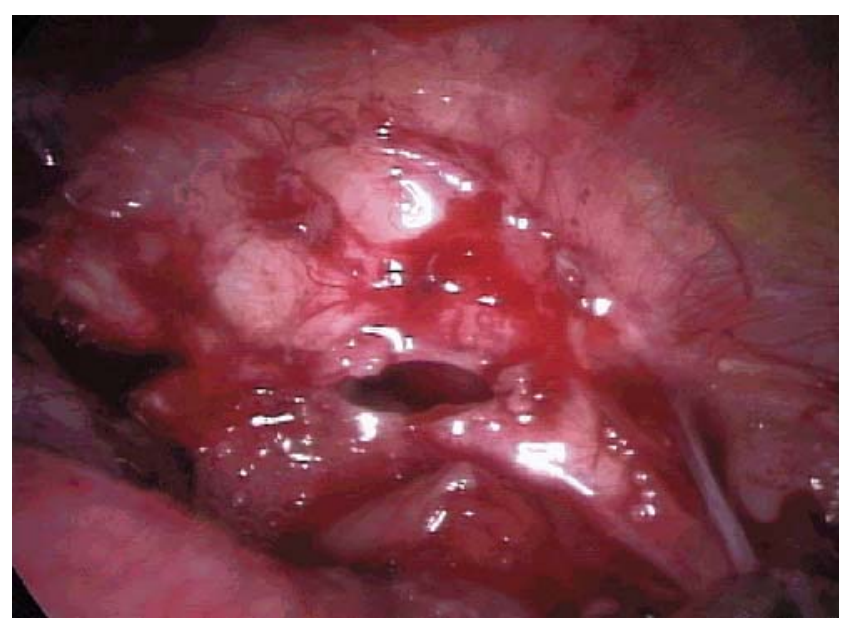

Fig. 2

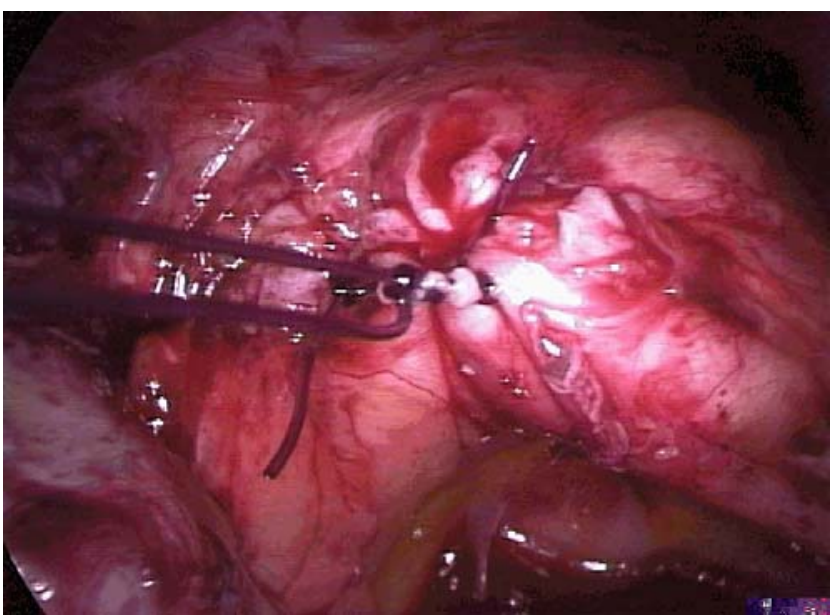

Fig. 3

secondary search of the listed references was also performed. There have been well over 100 cases in over 50 publications [1-53] reported in the literature since the condition was first described in 1902 [53]. Whilst the true incidence of tubal prolapse is unknown, Piacenza and Salsano [6] estimate that it occurs in approximately $1.3 \%$ of hysterectomies. Whilst most authors have described an increased frequency with vaginal hysterectomy [11, $14,21,26]$, a review of 8444 cases found 18 cases of prolapsed tube and the majority $(65 \%)$ were associated with abdominal hysterectomy [9]. This complication has also been reported via the combined laparovaginal route.

For a tubal prolapse to occur there must be a communication between the peritoneal cavity and the vagina. Thus, Fallopian tube prolapse has been variously associated with Filshie clip prolapse [11], ectopic and abdominal pregnancy [54, 55], torsion [52], pneumoperitoneum (post-coital) [39], abscess and fistula [38]. Occasional cases of true evisceration have also been reported following hysterectomy [56-58]. Whilst inflammation has been reported on biopsy and histopathology, associated salpingitis has been noted far less

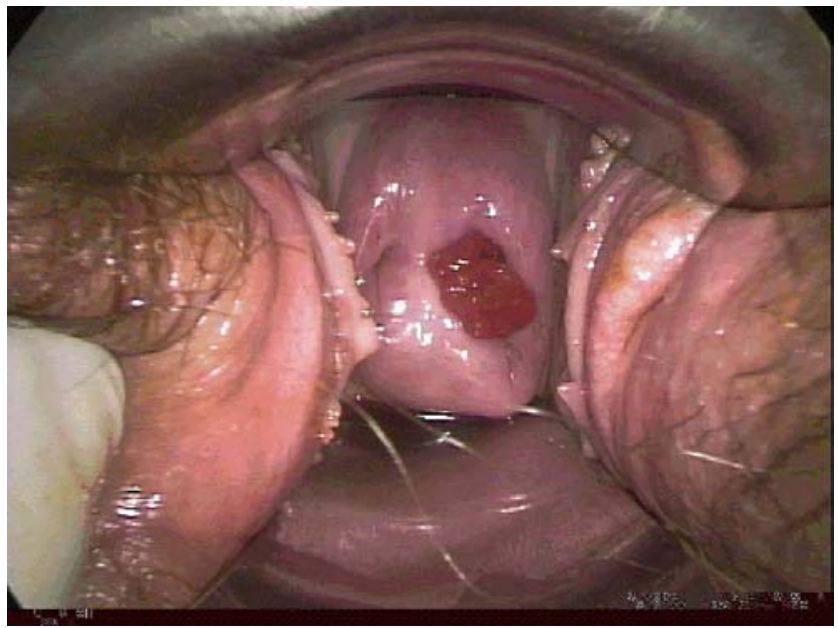

Fig. 4 


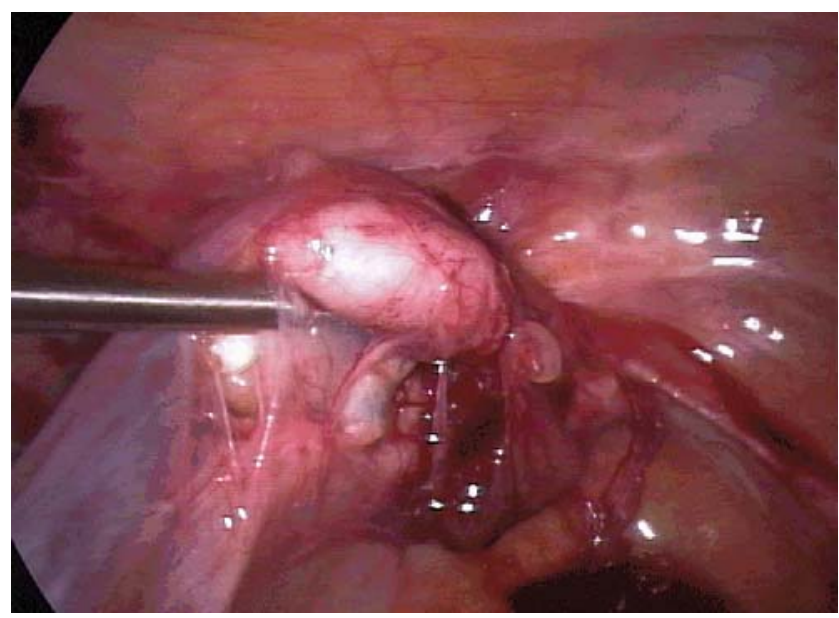

Fig. 5

commonly [10]. More recently, there has been a case of a herniation of the fimbrial end of the fallopian tube after a subtotal hysterectomy [3].

These two presentations of pyosalpinx are currently the only cases of tubal prolapse reported after a total laparoscopic hysterectomy. These cases were clinically more obvious, leading to rapid diagnosis and intervention. The symptomatology of the herniated tube is predominantly that of pain, dyspareunia and bleeding [12]. Other symptoms include leucorrhoea or a foul-smelling discharge, chronic midline or unilateral pelvic pain [14]. The presence of a malodorous discharge is a clear pointer to an infectious process. It should cause the gynaecologist, in the absence of a vulval or vaginal cause, to consider the possibility of a pyosalpinx. It is rare for this to be an incidental finding in an asymptomatic patient [46]. Although Ramin et al. [9] report that 5 of the 17 women in their series of 8444 cases with uterine tube prolapse were asymptomatic, it is not clear how these women were identified.

Vaginal palpation or manipulation of a visualized lesion may reproduce the pain experienced by the patient. The clinical findings are not always obvious. However, a lesion may resemble granulation tissue, or may actually be seen as the prolapsed fimbrial end of the uterine tube $[19,21]$. The time interval before clinical expression is variable and may be present within a few months (early prolapse) or as much as 28 years later [24] (late prolapse) such as in our first case. We theorize that when there is an early prolapse, it is likely to be associated with excessive physical activity or early sexual activity, leading to weakening of the vaginal vault scar. Our second patient was a grand multiparous woman. She was a difficult anaesthetic case, and was noted to be agitated in recovery.

Other predisposing factors have previously been proposed and discussed [6, 24, 36, 43, 44, 49]. These include insufficient preoperative vaginal preparation, difficult surgical procedure, postoperative fever, the formation of haematomas, an open vaginal cuff, low socioeconomic status, use of polyglactin polymer sutures, and use of transvaginal drains or packs. Muntz et al. [21], however, support the use of drains to prevent stagnation of any haematoserous fluid that has the potential to become infected. Though the postmenopausal period has been identified as a risk factor, there is a greater disposition towards younger patients [9]. Piacenza and Salsano [6] theorize that a tubal end would only be more likely to herniate if it was sufficiently long and mobile, accounting for the rarity of the condition. This is reasonable, given that not all women with discharge of vault haematomas end up having prolapsed tubes. There is disagreement as to which tube is more likely to prolapse $[9,44]$, and there would not appear to be any anatomical factor favouring one side or the other.

The diagnosis is difficult to make, suggesting the usefulness of biopsy of the vaginal vault and investigation by ultrasound, though Muntz et al. [21] did not find it useful in their two-patient case report as small specimens showing acute and chronic inflammatory changes could not distinguish it from simple granulation tissue. Nonetheless, histopathology has also erroneously diagnosed cases to be papillary adenocarcinoma [24] or granulation tissue [21] or other rarer diagnoses [8]. Wolfendale [27] describes typical cytology with small occasionally ciliated columnar cells with prominent nucleoli. However, columnar cells on a vault smear are usually associated with malignancy. Thus, we would recommend biopsy as the initial investigation in favour of cytology.

In these two cases, the infection leading to pyosalpinx was probably due to incarceration of the tube within the suture line of the vault or a progressive formation of a sinus in the vaginal vault. Microbial colonization is presumably exogenic since in the first case, the contralateral tube was free of infection. Thus, it is unlikely to have resulted from haematogenous spread.

Total salpingectomy is advocated as the optimal management as recurrent symptoms have been reported after partial salpingectomy [23, 29, 34]. This is clearly necessary where salpingitis and pyosalpinx are present. We agree with those authors who advocate salpingooophorectomy, even in younger age groups if the woman has finished her family, due to the concern that the ovary has been involved in inflammatory processes [14].

Abdominal and vaginal techniques have been used to treat the prolapse, and the combined laparoscopic-vaginal approach has been advocated to avoid a prolonged hospital stay [20, 29]. Laparoscopic management seems to be the best way to simultaneously make the diagnosis with certainty, explore the pelvic cavity, and carry out definitive treatment, under superior vision. In our two cases, the vault was reopened laparoscopically, and definitive treatment comprising salpingo-oophorectomy was undertaken. The vault was closed in one layer with poliglecaprone 0 using interrupted figure-of-eight sutures in both patients. They had an uncomplicated postoperative course and were discharged the next day.

The importance of fascial approximation when closing the vaginal cuff has been emphasized [14, 46]. 
Peritonization was previously performed systematically in hysterectomies. However, it has been abandoned by many $[59,60]$. In the series of Ramin et al., 11 of the 18 cases had peritoneal closure, with five unknown. Thus, peritoneal closure does not seem to be protective, and the lack of peritonization in hysterectomies performed laparoscopically would not appear to be a risk factor for tubal prolapse [9].

Nonetheless, the prevention of this type of complication necessitates meticulous suturing of the vagina to ensure accurate approximation. We recommend a slow reabsorbable suture, and the utilization of local oestrogen therapy postoperatively where atrophy is clearly present in order to assist scar formation and healing. Some practitioners may favour systemic therapy. One can also perform bilateral ovariopexy, a technique initiated to prevent adnexal torsion after laparoscopic hysterectomy [61]. A total laparoscopic approach, in particular, gives the surgeon(s) the ability to visualize the vault at close quarters and ensures precise approximation of the vaginal cuff. The majority of pelvic adhesions can be dissected laparoscopically, and when infection is present, such as in our two patients, thorough irrigation of the pelvis can be performed under vision. Laparoscopy also enables the surgeon to enforce strict haemostasis making a drain unnecessary.

In conclusion, pyosalpinx associated with tubal prolapse after total hysterectomy is rare. Tubal prolapse associated with total laparoscopic hysterectomy has not been reported before, probably due to its more recent advent in laparoscopic gynaecology. The diagnosis can be difficult but may be made through a combination of clinical examination and findings on biopsy and ultrasound. Laparoscopy is a suitable tool to both diagnose and treat the condition in its entirety, without resorting to a vaginal approach. Careful and precise surgical technique in performing the hysterectomy may prevent the problem from occurring.

\section{References}

1. Noor S, Halimi M, Faiz NR, Sadaf F, Akhtar P, Zahoor S (2004) Fallopian tube prolapse after abdominal hysterectomy. J Ayub Med Coll Abbottabad 16(2):78-79

2. Tjalma WA (2003) Surgical management of tubal prolapse. Int J Gynaecol Obstet 83(2):207-208

3. de Kroon CD, Bergman I, Westenberg S, van Eyk H, Thurkow AL (2003) Prolapse of the uterine tube after subtotal hysterectomy. BJOG 110(3):333-334

4. Jashnani KD, Naik LP (2002) Prolapsed fallopian tube with squamous metaplasia. J Postgrad Med 48(3):241-242

5. Lavy Y, Hamani Y, Lev-Sagie A (2002) Fallopian tube prolapse after hysterectomy (in Hebrew). Harefuah 141(6):530531,578

6. Piacenza JM, Salsano F (2001) Post-hysterectomy fallopian tube prolapse. Eur J Obstet Gynecol Reprod Biol 98(2):253-255

7. De Clippel K, Coenen M, Bhal PS, Amso N (2001) Fallopian tube prolapse following abdominal hysterectomy. Aust N Z J Obstet Gynaecol 41(1):106-108
8. Michal M, Rokyta Z, Mejchar B, Pelikan K, Kummel M, Mukensnabl P (2000) Prolapse of the fallopian tube after hysterectomy associated with exuberant angiomyofibroblastic stroma response: a diagnostic pitfall. Virchows Arch 437(4):436-439

9. Ramin SM, Ramin KD, Hemsell DL (1999) Fallopian tube prolapse after hysterectomy. South Med J 92(10):963-966

10. Lefrancq T, Orain I, Michalak S, Hourseau M, Fetissof F (1999) Herpetic salpingitis and fallopian tube prolapse. Histopathology 34(6):548-550

11. Buckett W, Carlin A, Kingsland C (1998) Prolapse of Filshie clips following vaginal hysterectomy. Acta Obstet Gynecol Scand 77(4):471-472

12. Hernandez CR, Howard FM (1998) Management of tubal prolapse after hysterectomy. J Am Assoc Gynecol Laparosc 5(1):59-62

13. Aboud E (1997) Prolapse of the fallopian tube into the vaginal vault. Clin Exp Obstet Gynecol 24(2):116

14. Candiani GB, Candiani M (1996) Posthysterectomy fallopian tube herniation. A report of two cases. J Reprod Med 41(12):915-920

15. Jensen H, Rasmussen KL (1996) Prolapse of the salpinx after hysterectomy. Ugeskr Laeger 158(36):5040-5041

16. Pai RR, Flora, Lobo D, Chadaga RP, Furtado HJ, Raghuveer CV (1995) Fallopian tube prolapse following abdominal hysterectomy. J Indian Med Assoc 93(10):402

17. Koks C, Roumen F, Bouckaert P (1994) Prolapse of fallopian tube through the vaginal introitus following vaginal hysterectomy. J Gynecol Surg 10:271-276

18. Hellen EA, Coghill SB, Clark JV (1993) Prolapsed fallopian tube after abdominal hysterectomy: a report of the cytological findings. Cytopathology 4(3):181-185

19. Byrne DL, Edmonds DK (1989) Prolapse of the fallopian tube following abdominal hysterectomy. J R Soc Med 82(12):764-765

20. Letterie GS, Byron J, Salminen ER, Miyazawa K (1988) Laparoscopic management of fallopian tube prolapse. Obstet Gynecol 72(3 Pt 2):508-510

21. Muntz HG, Falkenberry S, Fuller AF Jr (1988) Fallopian tube prolapse after hysterectomy. A report of two cases. J Reprod Med 33(5):467-469

22. Dao AH, Cartwright PS (1987) Fallopian tube prolapse following abdominal hysterectomy. J Tenn Med Assoc 80(3):141142

23. Wetchler SJ, Hurt WG (1986) A technique for surgical correction of fallopian tube prolapse. Obstet Gynecol 67(5):747749

24. Wheelock JB, Schneider V, Goplerud DR (1985) Prolapsed fallopian tube masquerading as adenocarcinoma of the vagina in a postmenopausal woman. Gynecol Oncol 21(3):369-375

25. Zamberletti D, Fedele L, Marchini M, Cavalli G, Candiani GB (1983) Modifications of the endosalpinx at S.E.M. in a case of post-hysterectomy tubal prolapse. Acta Eur Fertil 14(6):395399

26. Bilodeau B (1982) Intravaginal prolapse of the fallopian tube following vaginal hysterectomy. Am J Obstet Gynecol 143(8):970-971

27. Wolfendale M (1980) Exfoliative cytology in a case of prolapsed fallopian tube. Acta Cytol 24(6):545-548

28. Thomson JD (1980) Fallopian tube prolapse after abdominal hysterectomy. Aust N Z J Obstet Gynaecol 20(3):187-188

29. Batty LH, Williams SB, Krantz KE (1980) Laparoscopic repair of the prolapsed fallopian tube. J Reprod Med 24(6):244 246

30. Novendstern J (1979) Prolapse of fallopian tube after abdominal hysterectomy. Am J Obstet Gynecol 135(8):1120

31. Zelenik JS (1977) Prolapse of fallopian tube into vaginal vault. Am J Obstet Gynecol 128(8):926-927

32. Carmichael DE (1976) Prolapse of the fallopian tube into the vaginal vault. Am J Obstet Gynecol 125(2):266-267

33. Velasquez V, Valenzuela M, Hess R, Arias C, Dabancens A (1976) Prolapse of the fallopian tube. Clinical case. Rev Chil Obstet Ginecol 41(5):295-297 
34. Sumathy V, Baucom K (1975) Prolapse of the fallopian tube following abdominal hysterectomy. Int J Gynaecol Obstet 13:273-275

35. Silverberg SG, Frable WJ (1974) Prolapse of fallopian tube into vaginal vault after hysterectomy. Histopathology, cytopathology, and differential diagnosis. Arch Pathol 97(2):100-103

36. Sapan IP, Solberg NS (1973) Prolapse of the uterine tube after abdominal hysterectomy. Obstet Gynecol 42(1):26-32

37. Ellsworth HS, Harris JW, McQuarrie HG, Stone RA, Anderson AE 3rd (1973) Prolapse of the fallopian tube following vaginal hysterectomy. JAMA 224(6):891-892

38. Bolognese RJ, Corson SL (1972) Bilateral salpingo-vaginal fistula. Int J Gynaecol Obstet 10:116-118

39. Tabrisky J, Mallin LP, Smith JA 3rd (1972) Pneumoperitoneum after coitus. A complication due to uterine tube prolapse after vaginal hysterectomy. Obstet Gynecol 40(2):218-220

40. Halpin TF (1971) Prolapse of the fallopian tube following abdominal hysterectomy. Am J Obstet Gynecol 110(6):880881

41. Murray RC, Bubala PG (1966) Tubal prolapse following vaginal hysterectomy. Report of 2 cases. Obstet Gynecol 27(2):271-274

42. Hirsch H, Wyatt L (1961) Prolapse of a fallopian tube after total abdominal hysterectomy. A report of one case. Am J Obstet Gynecol 82:938-939

43. Trussell RR, Taylor CW (1958) Prolapse of the fallopian tube following hysterectomy. J Obstet Gynaecol Br Emp 65(1):51-55

44. Symmonds RE, Counseller VS, Pratt JH (1957) Prolapse of a fallopian tube as a complication of hysterectomy; report of three cases. Am J Obstet Gynecol 74(1):214-217

45. Johnson WO (1956) Prolapse of fallopian tube after vaginal hysterectomy; report of three cases. J Ky State Med Assoc 54(6):503-505

46. Funnell JW, Kelso JW (1955) Prolapse of a fallopian tube into the vagina vault following hysterectomy. South Med J 48(7):681-686

47. Israel SL, Weber LL (1953) Prolapse of oviduct into vagina following vaginal hysterectomy. J Albert Einstein Med Cent (Phila) 1(4):168-170

48. Ferraris G (1952) Un raro reperto dopo colpoisterectomia: Il prolasso vaginale della tuba. Minerva Ginecol 4:666-668
49. McElin TW, Feris DO (1949) Prolapsed fallopian tube as a complication of vaginal hysterectomy: report of 2 cases. Proc Staff Meet Mayo Clin 24:447-452

50. Thunig LA (1943) Prolapse of the fimbriated end of the fallopian tube with vaginal bleeding following vaginal hysterectomy. Am J Obstet Gynecol 45:876-879

51. Radman H (1941) Prolapse of a fallopian tube following vaginal hysterectomy. Am J Obstet Gynecol 42:143-144

52. Bower JO, Pearce AE, Conway EW (1940) Prolapse and torsion of the right fallopian tube with vaginal bleeding following hysterectomy. Am J Obstet Gynaecol 40:1047-1050

53. Pozzi M (1902) Hernie de la trompe dans le vagin au niveau d'une cicatrice opératoire d'hystérectomie vaginale. C R Soc Obstet Gynaecol Paediatr 4:255-257

54. Isaacs JD Jr, Cesare CD Sr, Cowan BD (1996) Ectopic pregnancy following hysterectomy: an update for the 1990s. Obstet Gynecol 88(4 Pt 2):732

55. Arora VK (1983) Abdominal pregnancy following total hysterectomy. Int Surg 68(3):253-255

56. Narducci F, Sonoda Y, Lambaudie E, Leblanc E, Querleu D (2003) Vaginal evisceration after hysterectomy: the repair by a laparoscopic and vaginal approach with an omental flap. Gynecol Oncol 89(3):549-545

57. Ramirez PT, Klemer DP (2002) Vaginal evisceration after hysterectomy: a literature review. Obstet Gynecol Surv 57(7):462-467

58. Nezhat CH, Nezhat F, Seidman DS, Nezhat C (1996) Vaginal vault evisceration after total laparoscopic hysterectomy. Obstet Gynecol 87(5 Pt 2):868-870

59. Gupta JK, Dinas K, Khan KS (1998) To peritonealize or not to peritonealize? A randomized trial at abdominal hysterectomy. Am J Obstet Gynecol 178(4):796-800

60. Janschek EC, Hohlagschwandtner M, Nather A, Schindl M, Joura EA (2003) A study of non-closure of the peritoneum at vaginal hysterectomy. Arch Gynecol Obstet 267(4):213-216

61. Mashiach R, Canis M, Jardon K, Mage G, Pouly JL, Wattiez A (2004) Adnexal torsion after laparoscopic hysterectomy: description of seven cases. J Am Assoc Gynecol Laparosc 11(3):336-339 